\title{
'I wish I could shimmy like my sister Kate': Dance halls and dancing between the wars ${ }^{1}$
}

I'm looking for the Ogo-pogo, / The funny little Ogo-pogo.

His mother was a polliwog, his father was a whale,

I'm going to put a little bit of salt on his tail.

I want to find the Ogo-pogo/While he's playing on his old banjo.

The Lord Mayor of London,/ The Lord Mayor of London,

The Lord Mayor of London wants to put him in the Lord Mayor's show".

'The Ogo Pogo; The Funny Foxtrot'

WHEN MAX BYGRAVES sorrowfully announced in 1960 that 'they've changed our local palais into a bowling alley' he signalled the end of an institution that had been central to working-class and lower-middle class popular culture for four decades, or more. Most definitely, 'Fings Ain't What They Used to Be.' The advent of 'the palais' in the 1920s was dramatic and owed much to American entrepreneurship and American music, but there were other roots that reached back to the resort development of late-nineteenth century. Blackpool's ballrooms pointed the way to the future but, prior to 1914, most workingclass social dancing took place in smaller, less glamorous venues of varying degrees of respectability; and therein lay a problem. Charles Booth's observation about 'the scandal that surrounds all dancing saloons' still held true in the early twentieth century. 
Robert Roberts' father was not alone in believing that 'dancing rooms ... held the scum of the nation ... the lowest of the low. ${ }^{3}$

The attractiveness of social dancing was enhanced by the growing number of new dances, from America and Latin America, during the 1900s. Ragtime, with its emphasis on rhythm, and its popularity increased through the Moss Empires chain, brought with it various novelty dances variants of 'The Cakewalk,' numerous 'animal dances, and 'The Boston,' perhaps the most popular ragtime dance. ${ }^{4}$ The tango, increasingly tamed as it moved through pre-war Europe, still shocked many and then there was the foxtrot. The excitement created by the incessant 'ragging' or syncopation, the brash, gimmicky style of playing and the emphasis on physicality and personal expression created a fundamental challenge to the traditional working-class social dancing. In the sequence dancing of the early twentieth century (as later) the emphasis was upon an agreed script for each dance. ${ }^{5}$ There was novelty as new dances were introduced - 'The Military Two-Step' (1904), 'The Butterfly Gavotte' (1907) and, later 'The Square Tango' (1920), - but the intention remained unchanged. ${ }^{6}$ Each couple would perform the same combination of defined steps at the same time, and in the same direction. There was little, if any, scope for freedom of expression, and this was reinforced by conventions regarding movement around the dance floor. This was to change in a short space of time with the advent of an increasing number of more spontaneous dances specially devised for couples. ${ }^{7}$

The influx of Americans into Europe in the latter years of the Great War gave further momentum to this musical invasion; but, at the same time, it reinforced old fears about working-class leisure, especially unchaperoned women dancing in public; and created new ones, associated with 'nigger' music and illicit drugs. ${ }^{8}$ Sensationalist press coverage of a few highprofile London cases reinforced pessimists in their belief that English culture and morality was in grave peril. But, equally, for the entrepreneurs of leisure here was a golden opportunity.

\section{The dance hall boom}

The dance hall boom was spectacular. There was large-scale investment in new buildings, most notably the high-profile 
Hammersmith Palais, but also conversions of existing halls. Chains, notably Mecca and General Theatres, were at the forefront of developments. There was a local 'palais' in almost every town, from Burnley and Nelson in Lancashire to Exeter and Exmouth in Devon but there were also numerous other venues licensed for dancing for a working-class and lower middle-class clientele. ${ }^{9}$ In 1938 it was claimed that some three-quarters of a million people went to public dance halls each week. A year later Mass Observation estimated that over two-thirds of the population went dancing, with a hard core (about one in five, more likely middle-class) doing so on a regular basis. ${ }^{10}$ Demand was bolstered by the increase in real wages between the wars and, particularly by the widening employment opportunities for working-class women. ${ }^{11}$ The dance hall was patronised by men and women from different classes and different ages, but the most important single demographic was the young, unmarried working-class woman.

Dancing was a major element, second only to cinema, in the leisure life of the country. Although its long-term popularity was subject to short-term fluctuations, especially in the mid and late 1920s, it was largely 'recession proof.' ${ }^{12}$ The time-honoured link between dancing and companionship and courtship was made more attractive by the infectious nature of the new music and the opportunities for self-expression, unknown to an older generation of sequence dancers. The venues, especially the purpose-built dance halls, were a further attraction. Like the cinema, they were luxurious, bright and clean, and offered an escape from the mundane realities of daily life. The entertainment itself was good value for money in comparison with other attractions. ${ }^{13}$

\section{Civilizing and standardizing popular dance}

The introduction and dissemination of African-American influenced music was not without its problems. ${ }^{14}$ Ragtime and jazz, both poorly-defined but widely-used terms, had been enthusiastically received in certain quarters and roundly condemned in others. The outrage was rooted in assumptions about race and gender and found expression in a concern for the corruption of English popular music and dancing. Uncontrolled movement and inappropriate steps seemed to 
pose moral as well as artistic threats. For some the threats were 'jungle haunted monstrosities (J B Priestley), for others it was 'artistic Bolshevism' (Imperial Society of Teachers of Dancing) but for all critics it was a threat that had to be contained, neutralised and civilized.

Pre-war social dancing was dominated by the wealthy middle and upper classes; ballroom dancing was held in high esteem and the professional dance instructor a central figure. Even in the first decade of the twentieth century there were elite concerns that dancing standards were being eroded and action was needed to maintain and regulate them. The ISTD (the Imperial Society of Teachers of Dancers), was founded in 1904 in response to the proliferation of bad habits brought about by the degeneration of dancing into 'a mere pastime ... a vulgar romp' rather than being an 'Art.' ${ }^{\text {'5 }}$ The ISTD's purpose was 'to impart ... throughout the country a uniform method' centred on 'dignified dance movements.' It saw its role as positive and forward-looking, 'learning ... the newest dances and acquiring the most approved styles. ${ }^{16}$ Such was the perceived threat in the 1900 s that it was suggested that the "chief public schools ... [the educators of] future M.P.s, lawyers and military officers, should teach dancing. ${ }^{.17}$ The 'gay ballrooms where young people amuse themselves first and think about dancing style second' could not be tolerated. ${ }^{18}$ However, the problem of "slipshod" ways of holding partners, exacerbated by the fashion for 'backless gowns,' paled into insignificance when faced with the growing number of 'freak' steps, the 'abominable hops, jumps, springs and rushes' associated with 'the American Boston and Two-step', before the war, and, especially in the 1920s, 'the series of contortions without a vestige of grace, reminiscent of the Negro orgies from which it derives its creation,' otherwise known as the Charleston. ${ }^{19}$ There was a danger, at least in the eyes of Philip Richardson, the editor of Dancing Times, that old dances like the waltz would be swept to the side-lines as new dances brought chaos on the dance floor. ${ }^{20}$ Dance, ballroom dancing specifically, was conceived by the leading figures of the ISTD as 'Art' with an undisputed capital A. It was characterised by grace, self-control, self-restraint and properly executed steps in other words, respectability on the dance floor, ${ }^{21}$ Dance also 
carried important connotations regarding gender, class and (crudely defined) race. ${ }^{22}$ Potentially disruptive and corrupting elements, whether habitués of working-class dance halls or African-American musicians with their 'jungle' music and dancing, had to be neutralised. Loose dancing was seen as a sign of loose morals. Both had to be resisted, civilized and standardized. ${ }^{23}$

Members of the ISTD, and its supporters, saw themselves as both cultural and moral guardians of a distinctive and superior English approach. As early as 1920, dance instructors, meeting at Grafton Galleries, agreed 'to do their best to stamp out freak steps.'They established a committee to determine the approved steps for a variety of dances, including the foxtrot, which had been infiltrated and put in 'grave peril' by the scandalous 'shimmy.' Driven by Richardson, the ISTD established a ballroom branch in 1924. A key figure was Victor Silvester, a winner at the first world ballroom dancing championship in 1922 and again in 1924, for whom codification and its implementation became a life-time commitment. With others he determined not simply the appropriate steps and holds but also the appropriate tempi for a range of dances, notably the foxtrot, quickstep, waltz and tango, in what was to become known as 'the English' style. Charts were produced, textbooks written and the teachers of the ISTD were the missionaries sent out to spread the gospel through lessons and competitions. Silvester led by example through his strict-tempo records and radio performances. He was not alone. Santos Casani cooperated with British Pathé to produce newsreel dance lessons. Intention, no matter how determined, was no guarantee of success. The would-be saviours of English ballroom dancing faced two major problems that were not entirely within their control - dance bands and their leaders, and dancers.

The creation of Victor Silvester's orchestra was a response not simply to the perceived ill-discipline of American jazz musicians, adding or extending notes at will, but also to the various ways in which dance music was played, particularly by the big-name bands, led by Jack Hylton, Carroll Gibbons, Jack Payne and Ambrose. In certain respects they shared Silvester's concern with jazz and responded by modifying 'hot' music and, in Hylton's phrase, giving it 'the British touch ... which 
Americans and others never understood. ${ }^{24}$ However, these bands prided themselves on the skill and artistic merit of their musicianship. They were less concerned with playing simply for dancing than Silvester. They were playing for themselves and for a different, listening audience; and their emphasis was on musical virtuosity, within which steady, rather than strict, tempo was observed. A further complication came from the fact that the big dance bands were to be seen as well as heard. Nowhere was this clearer than at the end of 'He Played His Ukulele as the Ship Went Down,' when Jack Hylton's band sunk as one to the floor.

The demand for 'one original dancing time and speed' underpinned the ISTD decision to determine standardised tempi. ${ }^{25}$ The impact was limited. In 1926, Henry St. John Rumsey, a prolific writer on the subject and author of Ballroom Dancing, bemoaned the fact that dance bands were playing too fast for proper dancing. ${ }^{26}$ Almost a decade later Silvester was still complaining that those bands that looked to the armchair audience were playing standard dances at 'every conceivable speed,' thereby rendering them almost undanceable. ${ }^{27}$ Strict tempo à la Silvester offered a disciplined alternative, but it was as largely aimed at the myriad of bands that played for dancing across the country in dance halls, church halls and working men's clubs. These bands, semi-professional and amateur, maybe 20,000 in total, played for men and women who had come out for an evening's dancing. These were the people who 'patronise the obscure 'Bill Smith's Palais Five', because it is a real dance band which ... can play all the standard dances as a dance band should play them, so that it helps them to dance. ${ }^{28}$

However, even the virtues of 'Bill Smith's Palais Five' could not satisfy all paying customers, who flocked to the dance halls. Some welcomed the opportunity to put into practice the steps they had learned at a dance lesson or from an ISTD wallchart, and practiced in their bedroom. Others put off by the required conformity to prescribed steps, or simply deterred by their inability to master them, looked to simpler dancing styles, walking and shuffling in the eyes of critics. Yet others were enamoured of the 'freak' steps and not willing to conform to the instructions of 'civilizing' dance teachers or dance-hall MCs. This latter response could manifest itself in two ways. 
In its negative form, there was a refusal to take up certain dances advocated by the ISTD. The most notable failure was the tango. The shockingly immoral dance from Argentina had been partly civilized in pre-war Paris and London but the process of sanitization was completed in the mid-1920s. Despite a large-scale conference of dance teachers, the tango was received with a mixture of indifference and hostility. ${ }^{29}$ In its positive form, there was a dogged persistence to stay with dance steps proscribed by the authorities. The Charleston was widely criticised by custodians of 'the English' style. It was 'a dance with no single merit,' danced by silly and selfish men and women and resulting in bruised shins and-heaven forfend! - laddered stockings. But attempts to ban it failed dismally. MCs risked physical assault when trying to enforce Charleston bans as the fans of 'the kicking dance' asserted their right to self-expression on the dance floor. As Melody Maker reported, dancers at Stoke Newington 'felt so strongly that they even knocked the MC unconscious after his fifth attempt to stop them dancing the Charleston. ${ }^{30}$ The PCQ campaign - Please Charleston Quietly - failed as did attempts to develop a more decorous alternative in the form of the (oxymoronic) 'Flat Charleston.' Patrick Chalmers, a regular writer on dance in the Daily Mail in the 1920s, bemoaned 'Chaos on the Dance Floor,' but recognised that band leaders had to keep close 'to what the public's mood of the moment is demanding. ${ }^{31}$ And the public mood was demanding dances such as the 'Black Bottom,' because when 'the white peoples,' as he put it, 'catch the dance rhythms of the music, crooning of saxophones and tom-tom beat of drums, they find a greater exhilaration in it than they ever did in the more monotonous waltz, elaborate minuet or stately cotillion. ${ }^{32}$ There was no escaping the excitement of the music, the novelty of the sound and the freedom of 'freak' steps.

By the late 1930s there were signs of a reaction against the demands and sameness of the mainstream dances of the "English style, particularly the foxtrot. ${ }^{33}$ The technical requirements of dancing the Charleston or the Black Bottom, even the 'English style' foxtrots and waltzes were beyond the capabilities of many would-be dancers. Others saw these dances as boring. There was a demand for simpler but more enjoyable dancing, which 
was met by Mecca through a series of very basic novelty dances, the best-known of which was 'The Lambeth Walk.' Effectively a return to sequence dancing, it was a stunning success, driven by the full force of Mecca publicity, combined with some help from the BBC radio and television. ${ }^{34}$ The Chelsea Palace production of $M e$ and $M y$ Gal had been on the point of closure when a $\mathrm{BBC}$ radio broadcast from the theatre alerted thousands to the delights of the Lambeth Walk. ${ }^{35}$ The song was hugely successful - sales were on a par with the 1923 mega-hit 'Yes We Have No Bananas' - and the dance, with its 'jerky swagger, the 'thumbs-up gesture, and the handspreading Jewish 'Oi!' added to the popularity of the cheerful and cheeky-faced, Lupino, 'I'm a Cockney, born and bred', Lane. ${ }^{36}$ The Lambeth Walk was danced in halls across the land but, continuing an older tradition, it was also danced in the streets. ${ }^{37}$ It was one of a number of novelty dances introduced by Mecca. 'Under the Spreading Chestnut Tree,' boosted by alleged support from royalty, appealed across the respectable/ non-respectable divide and lived on as a children's party dance after the war; but the equally (in)authentic cockney 'Knees up, Mother Brown,' though easy to dance, 'never made the social grade,' because according to Graves and Hodge, 'the lifting of skirts... was a little too much.' ${ }^{38}$ Advertised as 'the latest pally dance,' the 'Park Parade' failed to achieve significant success, not helped by the relatively complexity of its steps. ${ }^{39}$ Similarly, 'The Handsome Territorial', despite being recorded by both Nat Gonella and Jack Hylton, soon faded from memory.

The Mecca boss, Carl Heimann, unashamedly exploited anti-Americanism by emphasizing the supposedly authentic English roots of 'The Lambeth Walk', as a 'Cockney' dance, notwithstanding the fact that the dance was choreographed by Adele England, who openly admitted that she had made no study of Cockney culture in general or Cockney dancing in particular. She claimed to have based the steps on what she knew to be popular in the present-day dance halls. In essence, the Lambeth Walk was a simple sequence dance that harked back to Edwardian years. More interesting, is the extent to which others bought into the myth of the Lambeth Walk. For a supposedly place-specific cultural phenomenon, it quickly spread across the country, transmuting into local variations 
from the Margate Walk to the Blackpool Walk. However, the specific temporal context, the impending sense of threat as international tensions increased, played its part. The chirpy, defiant figure, strutting across the stage in a jaunty dance that, eventually, became a communal strut and an ebullient 'Oi!' or 'Och Aye' in Scotland! - was well suited to the times. The cross-class camaraderie and sense of community portrayed in the film version of $M e$ and $M y$ Gal was patent nonsense but in real-life dance halls in Lambeth and Luton or Leeds and Liverpool, it was easier to believe that the experience of local community was a microcosm of national unity. The commercial instincts of the Mecca bosses and their constructed popular culture was taken up by a public to a degree that surprised its creators, as for unanticipated reasons, the public took to the song and dance in an unprecedented manner.

\section{Dance and society}

Countering the threat of 'Americanization' attracted considerable attention but there were more mundane concerns for the various defenders of English dancing standards. Girls lacking buoyancy and leaden men resulted in 'aimless perambulation' on the dance floor. ${ }^{40}$ In fact, the 'problem' reflected two important factors: the democratising of dancing and the social functions of the dance hall. Dancing fulfilled a variety of functions. The dance hall offered an escape from daily life at work and at home. The new palais offered a glimpse of a more luxurious lifestyle comparable to that of Dickens'Victorian gin-palaces. The extent to which this was achieved in the smaller dance halls is debatable. Unlike the Ritz, Manchester, Salford's 'Broadway' was described as 'only a large house, with a wall in between knocked down.'The band comprised 'a piano, drums and clarinet ... and it used to be murder in there, they'd be packed, sweating cobs. ${ }^{41}$

Dancing, particularly to the new music, was a form of selfexpression and physical activity; but, more so, the dance hall was a venue for social interaction, providing an alcohol-free alternative to the more male and adult-oriented public house. It was a more attractive and less restrictive place for the young and single to meet members of the opposite sex. It was part of the transition to adulthood and a working life, in which one 
learnt such adult activities as smoking, betting and dancing. In fact, learning a few dance steps was often easier than learning the social conventions that went with young adult life. Though never exclusively for the young, the dance hall culture of the 1920 s and 1930s pre-figured the more explicit youth culture of the post-second world war years.

For the young (and not so young) singles the dance hall was crucial in the often-turbulent process of meeting, dating and marrying, which remained the expectation of the vast bulk of the population. Despite the presence of MCs, charged with maintaining decency on the dance floor and the presence of parents waiting outside at the end of the entertainment - or the strict admonition to be 'home at $10 \ldots$ and not a minute later!' - the dance hall was a more relaxed and romantic place in which to meet a future partner. There was a recognised code of behaviour. It was for men to pluck up courage and ask a woman to dance, except, of course, if it was a 'ladies' excuse me,' and it was acceptable to move from partner to partner, though eventually a couple would emerge to dance together for the rest of the evening. Inappropriate behaviour was frowned upon, irrespective of the presence of MCs and bouncers. ${ }^{42}$ Not everyone was looking for a partner - many young women, simply enjoying an evening out, dancing with each other - but many did. Inadvertently, when purists condemned dancing as 'hugging to music,' they hit upon its prime purpose for many participants.

There was a cluster of inter-related concerns about the position of women in post-war society that coloured the response to the dance hall. The re-appearance of the 'surplus woman' problem, the small but increasing number of divorces and separations and falling birth rates gave rise to fears about marriage and the family, those twin rocks on which the stability of society allegedly rested. ${ }^{43}$ Dimly lit halls and dances that encouraged physical contact merely reinforced negative preconceptions; so too did the high-profile and exaggerated preoccupation with night clubs. To have the Home Secretary condemn them as 'plague spots' and the National Vigilance Society resurrecting the cry of 'White Slavery' in relation to the presence of 'dance hostesses,' confirmed the clubs' sleazy reputation. The fact that 'dance hostesses' could also be found 
in many ordinary dance halls seemingly demonstrated that the contagion was not confined to the capital. The extent to which people bought into such sensationalism is open to question. The immorality of London might appear plausible to an observer from Barnsley or Buckingham, but most were aware that the majority of local dance halls were, if not respectable, at least not 'wild.' Similarly, the claims that dancing contributed to the feminization of men (not to mention the masculinization of women), thereby threatening the institutions of marriage and the family, did not stand up to scrutiny. Entrepreneurs of leisure, conscious of the heightened awareness of licensing authorities, took measures to ensure they did not lose their licences. Other interested parties, not least parents, played their part in ensuring that 'the problem' remained something 'other' that happened in a different part of town or another city. Most importantly, for the vast majority of young people who flocked to the dance halls, beyond the immediate aim of a good night out, their medium-term hope and expectation was to meet a partner and get married. Irrespective of the promarriage/family propaganda of the inter-war years, there was an underlying social conservatism in that inter-war youth were not set on abolishing marriage or overthrowing the family. ${ }^{44}$

However, there was a more progressive attitude towards the position of women in society, of which women on the dance floor was a part. For a variety of socio-economic reasons, women were less constrained than they had been before the Great War. Irrespective of the high-profile developments, such as the enfranchisement of women, completed in 1928, or changes in the divorce laws in 1923 and 1937, there were greater opportunities in terms of work and leisure, particularly for young, unmarried women. The importance of the contribution of the dance hall is open to debate. The most positive view has been expressed by James Nott, for whom dancing and the dance hall was for women 'a wholly liberating experience [which] played a significant role in their struggle for emancipation. ${ }^{45} \mathrm{He}$ argues that dancing was more than escape or exercise, offering opportunities for self-expression and enhancing self-worth. The whole experience of 'going out', from hairstyle and make-up to clothing and footwear gave rise to an image of what being feminine meant that contrasted starkly with that of pre-war 
years. Dance halls, as well as being more feminine (or at least less masculine) than other leisure locations, offered women a degree of control, not least through the right to refuse a second dance, or even to dance at all in the first place. At the same time, the opportunity to develop new codes of behaviour and to construct different (or at least modified) gender roles, contributed to a broader redefinition of masculinity, following on the experience of the war, in which some of its more toxic elements were shed. However, the case can be overstated. The new freedom for women was relatively short-lived. Marriage, for practical and ideological reasons, drastically reduced women's opportunity to go out to a dance. ${ }^{46}$ Even for single women, the expanding opportunities to create a new image could easily degenerate into the tyranny of fashion. Similarly, the 'natural' ability of women reinforced gender stereotypes. Further, many old attitudes persisted into the 1950s, at least. The dance hall phenomenon of the inter-war years was clearly important but there is a danger of allowing the novelty of change to overshadow more mundane continuity.

\section{Dance and a common popular culture}

The opening decades of the twentieth century saw a significant broadening of the range of popular music and an equally significant expansion of the means whereby this music was disseminated. Despite often exaggerated complaints about 'Americanization,' there was a process of modification, accommodation and fusion whereby new dances and new styles of playing developed and became a new norm. This process was, at times, problematic, not least in its racial stereotyping, uneven over time and region, and incomplete. Nonetheless, there could be little doubt that, by the late 1930 s, a significantly different culture was in the ascendancy. The same dance music could be heard across the country via the $\mathrm{BBC}$, or at the cinema, approximately the same dance steps were being attempted to the sound of numerous bands, using the same sheet music. To that extent, a common culture evolved that fused different elements from both sides of the Atlantic. Jazz music was tamed, jazz dances made less 'wild.' The old sequence dancing had been marginalised (until 'The Lambeth Walk') and the new 'English style,' of playing and dancing was less sedate, more 
'wild,' than it would otherwise have been. As Hylton boasted, his style of 'symphonic syncopation ... makes a subtle appeal to our British temperament ... [and] is fast becoming a truly national music. ${ }^{47}$ In similar vein, Mecca founder, Carl Heimann claimed there was 'no differentiation between the classes' on Mecca's dance floors. And yet the evidence of the halls pointed to a different conclusion. There were meaningful regional and sub-regional variations between and within towns and cities. In most towns there were different dance halls catering for different social groups, contrary to Heimann's assertion. Even within a specific dance hall, some evenings were given over to 'Old Time Dancing,' which catered for older dancers, while others catered for younger dancers. ${ }^{48}$ Additionally dancing was a gendered experience. The idea of 'cultures in common,' better captures the varied but complementary range of dance cultures that emerged in the inter-war years. ${ }^{49}$

\section{Some concluding observations}

The importance of the dance hall in working-class, and lower middle-class, popular culture is difficult to overstate. Only the cinema rivalled it in the new leisure of the interwar years. Given the pre-war hostility to such venues, and its continuation in some quarters afterwards, the dance hall boom speaks volumes for the strength of popular demand and entrepreneurial responsiveness. The dance hall was an important venue in which adolescent rites of passage were navigated. Concerns about immorality surfaced periodically, but spoke more of the observer than the observed, whose codes of behaviour, often unnoticed by their critics, were ultimately conservative. Love and marriage, aided by popular songs of the day, survived the threat of the dance hall. It was also an important site in a growing culture war against 'Americanization' but one which demonstrated the power of the consumer. Popular leisure reformers struggled to ban, or even tame, the Charleston as long as dancers demanded it. Similarly, while the anti-American, but inauthentic cockney dance, 'The Lambeth Walk' was taken up, and adapted, with enthusiasm, attempts to get people dancing to the 'Park Parade' failed dismally. 


\section{Endnotes}

1 The focus of this chapter is largely on the dance hall. There were other important venues and forms of dances, most notably the ceilidhs that were important for the Irish communities in England.

2 The original musical was produced by Joan Littlewood at the Theatre Royal, Stratford East but opened in the West End at the Garrick Theatre in February 1960. Bygrave's recording of the title song was bowdlerised for popular commercial consumption.

3 R Roberts, A Ragged Schooling, London, Fontana, p.179

4 P Buckman, Let's Dance: Social, Ballroom and Folk Dancing, London, Penguin, 1978 and T J Buckland, 'Dancing Out of Time: The Forgotten Boston of Edwardian England,' in S Dodds \& S C Cook, Bodies of Sound: studies across popular music and dance, Farnham, Ashgate, 2013, pp.55-72

5 T A Whitworth, A History of Sequence Dancing: Fashionable Bodies in England, 1870 -1920, Chesterfield, Whitworth, 1995 and T J Buckland, Society

Dancing, Basingstoke, Palgrave, 2011

6 For a fuller discussion see Whitworth, History of Sequence Dancing.

7 J Nott, 'Contesting Popular Dancing and Dance Music during the 1920s,' Cultural and Social History, 2013, 10(3), pp. 439-56. at pp. 439-40

8 M Kohn, Dope Girls: The Birth of the British Drug Underworld, London, Granta Books, 2001

9 For details see J Nott, Going to the Palais: A Social and Cultural History of Dancing and Dance Halls in Britain, 1918-1960, Oxford University Press, 2015. In the early 1930s, Rochdale, with a population of c.100,000 had six dance venues before the construction of its first purpose-built hall in 1934, J Stevenson, British Society, London, Penguin, 1984, p.398

10 The comparative figures for working-class and middle-class respondents respectively were $76 \%$ and $67 \%$ who went dancing and $21 \%$ and $24 \%$ who went regularly. Nott, Going to the Palais, p.38

11 There were deprived areas (including those with employment opportunities for women) in which fewer people could afford the entry price to a dance hall but there were other areas of relative prosperity, especially those associated with the new, light industries. In addition, the fall in the cost of living enhanced the purchasing power of all wage earners.

12 Nott, Going to the Palais, p. 25

13 Attendance at a weekday dance hall (probably about 3d) cost less than the cinema (around 6d) or attendance at a football match (around 6d to $2 \mathrm{~s}$ ). See S G Jones, Workers At Play, London, Routledge, Kegan \& Paul, 1986, p.14

14 As early as the 1890s, the Musicians' Union was worried that European musicians were coming to the country to the detriment of their members. The focus shifted to American jazz bands (as well as foreign orchestras) after the Great War when problems were exacerbated by the success of cinema, not to mention the cheap competition from police and military bands. See M Cloonan and M Brennan, 'Alien invasions: the British Musicians' Union and foreign musicians,' Popular Music, 2013, 32(2), pp.277-295 
15 G Butterfield, The degeneracy of dancing,' Dancing Journal, 1908, pp2-3 cited in T Creswell, "'You cannot shake that shimmie here": producing mobility on the dance floor,' Cultural Geographies, 2006 (13), pp.56-77 at p.65

16 See report in Daily Mail, 16 May 1906

17 Daily Mail, 16 May 1906. Eton, Harrow, Rugby and Marlborough were mentioned by name but not Winchester.

18 Daily Mail, 1 March 1924

19 Dancing Journal, 1911, p.15 cited in Cresswell, 'You cannot shake that "shimmie" here' p.65. Daily Mail, 26 July 1920 and 26 April 1926

20 T J Buckland, 'How the Waltz was Won:Transmutations and the Acquisition of Style in Early English Modern Ballroom Dancing,' Dance Research, 2018, 36(2), pp.1-50

21 In Notts' phrase 'a Terpisichorean equivalent of the "stiff upper lip." Nott, 'Contesting' p.443

22 For a good concise introduction see Cresswell, 'You cannot shake that "shimmie" here' pp.56-9.

23 The language with which 'freak' dances were condemned was telling - they were 'ungraceful, awkward, even indecent.'

24 J Hylton, 'The British Touch,' Gramophone, Sept. 1926, p.146 cited in Nott, 'Contesting' p. 445

25 The agreed limits were: tango to be played 30-2 bars per minute, the waltz 36-8, the foxtrot 38-42 and the quickstep 54-6.

26 Daily Mail 8 July 1926

27 V Silvester, 'What is your opinion?' Dance Journal, 1956, pp.105-6 cited in Cresswell, "You cannot shake that "shimmie" here' p.69

28 Dancing Times, November 1928, p.171 cited in Nott 'Contesting' p.449

29 Other failures include the Java (1924), the Mayfair (1927), the Midway Rhythm (1928) and the Six Eight (1929).

30 Cited in Nott, Going to the Palais, p.130

31 Daily Mail, 28 April 1927

32 Daily Mail, 13 November 1926

33 Even in the mid-1920s H St John Rumsey was complaining that there were too many foxtrots. Daily Mail, 22 July 1926

34 A Abra, 'Doing the Lambeth Walk: Novelty Dances and the British Nation,' Twentieth Century British History, 20(3) 2009, pp.346-69

35 R Graves \& A Hodge, The Long Weekend, 1st published 1940, London, Penguin, 1971, p.383. See https://www.youtube.com/ watch? ${ }_{\mathrm{v}}=$ Mc6XUus5IC4 not least for some fascinating French dubbing!

36 Graves \& Hodge, Long Weekend, p.384

37 See also A Davies, Leisure, Gender and Poverty: Working-class culture in Salford and Manchester, 1900-1939, Open University Press, Buckingham, 1992,, p.173

38 Graves \& Hodge, Long Weekend, p.385 and see https://www.youtube.com/ watch? $\mathrm{v}=\mathrm{BNpP}-\mathrm{jDbgI}$

39 See https://www.britishpathe.com/video/the-park-parade/query/dance

40 Daily Mail, 7 January 1931

41 Davies, Leisure, Gender and Poverty: p.90. See also R Roberts, $A$ ragged schooling: Growing up in the classic slum, Manchester University Press 1976 for the hierarchy of dance halls in Salford and Manchester. 
42 There was a concern that the seedier dance halls were also associated with gang violence. The evidence from Manchester and Salford suggests trouble was sporadic and not on the same scale as the pre-war Scuttler troubles. Davies, Leisure, Gender and Poverty, p93-4. For scuttlers see A Davies, The Gangs of Manchester, Milo Books, Preston, 2008

43 See also the oral testimony quoted in Davies, Leisure, Gender and Poverty pp.89-90

44 Nott, Going to the Palais, p.303, who suggests that the dance hall, as well as entrenching marriage, 'probably extended its life too.'

45 Nott, Going to the Palais, p.300

46 Davies, Leisure, Gender and Poverty, p.57, argues that the growth of commercialized leisure barely affected the weekly routines of some, especially married working-class women. See also Langhamer, 'Women and Leisure.' As well as restrictions on time as marital responsibilities increased, dancing was seen as less appropriate after marriage. Though older women, often with their daughters, returned to the dance hall, it was probably easier for most married women to incorporate the cinema into their limited leisure time.

47 Hylton, 'British Touch' in Nott 'Contesting Popular Dancing,' p.445

48 J Nott, Music for the People: Popular Music and Dance in Interwar Britain, Oxford University Press, 2002, p.182

49 Nott, Going to the Palais, p.305. 